\title{
Blood Pressure Control and Stroke: An Ounce of Prevention is Worth a Pound of Cure
}

\author{
Anne D. Leonard, RN, BSN, MPH, and Robin L. Brey, MD
}

A stroke, or brain attack, is caused by the sudden loss of blood flow to the brain or bleeding inside the head. A stroke can result in brain damage that causes disability or even death. By far the most common cause of stroke is high blood pressure, also called hypertension. More information about stroke and the conditions that increase the risk for stroke can be found on the next page.

Blood pressure readings of greater than or equal to $140 \mathrm{~mm}$ of mercury $(\mathrm{mm} \mathrm{Hg}$ ) for the top number (called the systolic blood pressure) and greater than or equal to $90 \mathrm{~mm} \mathrm{Hg}$ for the bottom number (called the diastolic blood pressure) indicate high blood pressure or hypertension. If blood pressure remains at this level or higher over years, serious damage is done to the blood vessels of the body. The figure compares a blood vessel damaged by hypertension with a normal healthy blood vessel. When blood vessels are damaged, blood cannot flow freely to vital organs. If blood flow is cut off completely, a brain attack occurs.

Small increases in blood pressure can dramatically increase a person's risk of stroke. In one study, for every $10 \mathrm{~mm} \mathrm{Hg}$ increase in the systolic blood pressure over normal, the risk of stroke increased by $28 \%$. This means that someone with a systolic blood pressure of $170 \mathrm{~mm} \mathrm{Hg}$ has an $84 \%$ greater chance of having a stroke than someone with a systolic blood pressure of less than $140 \mathrm{~mm} \mathrm{Hg}$. Despite this, many people who have had a stroke or heart attack continue to live with high blood pressure. In this issue of Neurology, Messerli and colleagues (Messerli FH, Hanley DF, Gorelick PB.
Blood Pressure Control in Stroke Patients: What should the Consulting Neurologist Advise? Neurology 2002; 59:23-25) review the recent information about blood pressure control and the risk for stroke. Only one study so far has carefully evaluated whether controlling blood pressure in a person who has already had a stroke will lower their risk for having another stroke. This information comes from the Perindopril Protection Against Recurrent Stroke (PROGRESS) trial.

The PROGRESS trial took place in 172 medical centers in Asia, Australia, and Europe and included 6,105 stroke patients studied for over 4 years. Half of the patients were given blood pressure lowering medication and half got placebo (inactive medication). In the group given active blood pressure lowering medication, some patients got one type (perindopril, an angiotensin converting enzyme--type medication) and some got two types (perindopril and indapamide, a diuretic-type medication, or "water pill"). It was up to the patient's doctor to decide whether they would be given one or two types of blood pressure lowering medication. In the group on two blood pressure lowering medications, the systolic blood pressure dropped an average of $12 \mathrm{mmHg}$ compared with the placebo group. This drop was even seen in patients who had normal blood pressure to begin with. In addition, patients on two medications had $43 \%$ fewer strokes. In the group on only one blood pressure lowering medication systolic pressure did not drop significantly and the risk for stroke was not reduced. This means treatments that effectively reduce high blood pressure also prevent strokes!

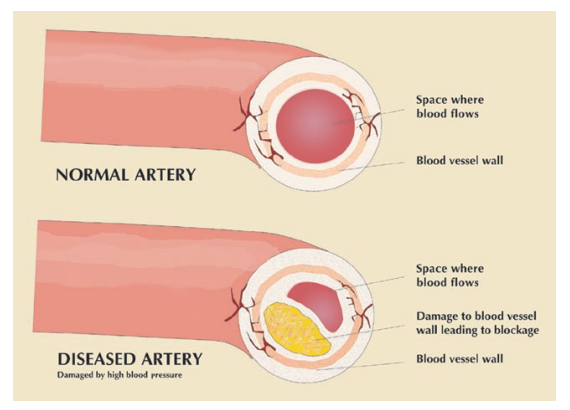

Hypertension is sometimes called the "Silent Killer" because it does not usually lead to symptoms that make a person feel sick. Sometimes, even when high blood pressure is discovered, people do not take their medications as they should because they are afraid of side effects. One side effect may be too low blood pressure that may cause dizziness and a risk of falling, especially in the elderly. However, this was not a big problem in the PROGRESS trial probably because blood pressure was not lowered too much. It is important to discuss side effects and other concerns with a doctor or nurse because there may be another type of blood pressure lowering medication that will not cause problems. Work with your doctor to learn the best way of keeping your blood pressure under control and reducing your risk of stroke. Also ask about other things you can do to lower your risk of stroke, such as stopping smoking, getting regular exercise, and following a healthy diet. Stroke prevention is one of the best examples of the old saying "an ounce of prevention is worth a pound of cure"! 


\section{NEUROLOGY Patient Page - ABOUT STROKE}

WHAT IS STROKE? A stroke, or brain attack, is caused by the sudden loss of blood flow to the brain or bleeding inside the head. A stroke can cause brain cells to die. This damage can cause paralysis, speech problems, loss of feeling, memory and reasoning problems, coma, and possibly death. Fortunately, there are effective ways to prevent stroke. If you develop a stroke, seeking immediate medical attention can help reduce your chances of death and disability.

How Common Is Stroke? Every year, about 750,000 people in the United States suffer a stroke and about 160,000 die. Stroke is the nation's number three killer after heart disease and cancer. Stroke is the number one cause of adult disability.

Stroke Is an Emergency. Call 911 immediately if you or someone you know experiences any of the above warning signs. Jot down the time the symptoms started. Sometimes these warning signs last for only a few minutes and then stop. But, even if that happens or if you feel better, call 911 for help.

\section{RISK FACTORS FOR STROKE THAT CAN BE TREATED OR CHANGED}

- High blood pressure

- Atrial fibrillation (an irregular heart beat)

- Diabetes

- Cigarette smoking

- Hyperlipidemia (high fat level in the blood)

- Alcohol abuse

- Obesity

- Sickle cell disease

\section{WHAT CAUSES A STROKE?}

There are two types of stroke or brain attack. Ischemic stroke is caused by an interruption of blood flow to the brain. Hemorrhagic stroke is caused by bleeding inside the brain.

Eighty percent of all strokes are ischemic. Ischemic stroke can be caused by narrowing of the large arteries to the brain, also known as atherosclerosis. If a clot forms in the neck vessels, pieces can break off and block a brain blood vessel. Clots may also form in the heart and travel by blood flow to the brain vessels where they become lodged.

Hemorrhagic stroke is caused by the bursting of a blood vessel in the brain. It accounts for $20 \%$ of strokes. Subarachnoid hemorrhage occurs when there are weak spots on brain arteries (aneurysms) that burst and cover the brain with blood. Blood vessels in the brain can also burst if they are weakened by high blood pressure, diabetes, and aging. Severe headache usually occurs with this type of stroke, as well as impaired consciousness and vomiting.

\section{WHAT ARE THE TREAT- MENTS FOR STROKE?}

Immediate medical care is critical for the person who is having a stroke or brain attack. New treatments work only if given within a few hours after the onset of a stroke. For example, a clot-busting drug must be given within three hours of stroke onset.

\section{HOW IS STROKE PRE- VENTED?}

Some risk factors-age, sex, race, and a history of stroke in the family-cannot be changed. However, many others can be controlled. Most controllable risk factors relate to the health of the heart and blood vessels. The following can help prevent stroke:

- Having regular medical check-ups

- Controlling high blood pressure

- Not smoking-stopping if you do

- Treating heart disease, especially an irregular heart beat called atrial fibrillation

- Improving diet: Avoid excess fat, salt, and alcohol

- Exercising

- Controlling diabetes

- Seeking immediate medical attention for warning signs of stroke

FOR MORE INFORMATION:

American Stroke Association, a Division of the American Heart Association

http://www.strokeassociation.org

National Stroke Association

http://www.stroke.org

AAN: Professional Information

http://www.aan.com

AAN: Patient Education

http://www.thebrainmatters.org 


\section{Neurology}

\section{Blood Pressure Control and Stroke: An Ounce of Prevention is Worth a Pound of Cure Anne D. Leonard and Robin L. Brey \\ Neurology 2002;59;E1-E2}

\section{This information is current as of July 9, 2002}

\section{Updated Information \& Services}

\section{Citations}

Permissions \& Licensing

Reprints including high resolution figures, can be found at: http://n.neurology.org/content/59/1/E1.full

This article has been cited by 2 HighWire-hosted articles: http://n.neurology.org/content/59/1/E1.full\#\#otherarticles

Information about reproducing this article in parts (figures,tables) or in its entirety can be found online at:

http://www.neurology.org/about/about_the_journal\#permissions

Information about ordering reprints can be found online: http://n.neurology.org/subscribers/advertise

Neurology ${ }^{\circledR}$ is the official journal of the American Academy of Neurology. Published continuously since 1951, it is now a weekly with 48 issues per year. Copyright . All rights reserved. Print ISSN: 0028-3878. Online ISSN: $1526-632 \mathrm{X}$

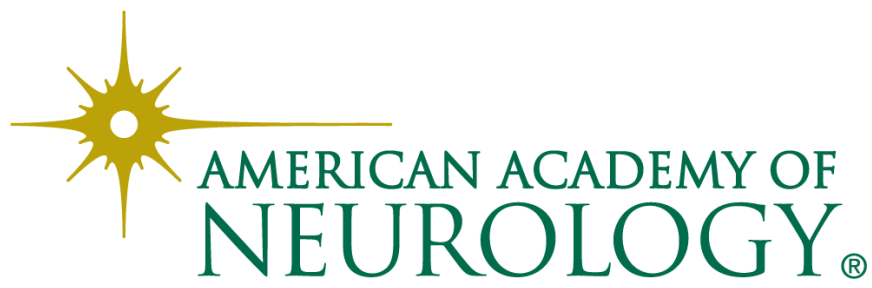

